\title{
Deteksi Objek Manusia Pada Image Dengan Metode Thinning Berdasarkan Local Maxima
}

\author{
Mawaddah Harahap**1, Erik Sartana Agustia ${ }^{2}$, Muhammad Marsyal Lubis ${ }^{3}$, Apriandi ${ }^{4}$, \\ Alvin Anggara ${ }^{5}$ \\ 1,2,3,4,5 Universitas Prima Indonesia; Jalan Sekip Simpang Sekambing, (061) 4578890 \\ 1,2,3,4,5 Program Studi Teknik Informatika, FTIK Universitas Prima Indonesia, Medan \\ e-mail: *1 mawaddah@ unprimdn.ac.id, ${ }^{2}$ erick.sartana@gmail.com, \\ ${ }^{3}$ Muhammad.marsyal@myself.com, ${ }^{4}$ freendi3@gmail.com, ${ }^{5}$ alvinanggara51@gmail.com
}

\begin{abstract}
Abstrak
Tujuan dari deteksi objek manusia adalah untuk mengidentifikasi objek manusia dalam image. Adanya perubahan objek manusia yang dipengaruhi oleh faktor-faktor internal seperti ekspresi wajah, bentuk tubuh, warna kulit, dan pergerakan badan serta dipengaruhi oleh faktor eksternal seperti kondisi pencahayaan, latar belakang yang bervariasi dan sudut pengambilan image. Mendeteksi objek manusia terhadap beberapa kondisi seperti didapatkan pada image yang berisi lebih dari satu objek, dan ukuran objek yang bervariasi didalam image. Penelitian ini bertujuan untuk menganalisis dan merancang aplikaasi untuk mendeteksi objek manusia yang ada dalam image. Algoritma thinning digunakan untuk pengenalan pola objek manusia dari satu image untuk gambar yang lain agar menyamakan objek piksel untuk pendeteksian yang maksimal. Local maxima digunakan sebagai fungsi untuk memaksimumkan pencarian piksel pada objek dalam image untuk mempermudah dan mempercepat deteksi image.
\end{abstract}

Kata kunci-Algoritma thinning, Local maxima, objek manusia

\section{Abstract}

The aim to detection human object is to identifying human object in image. There is a change human object affected by internal factors like face expression, body shape, skin color, and movement body and affected by external factor likes lighting condition, background which varies and corner taking image. The detect human object towards some condition likes obtained on image which containts more than one object, and object size which varies in image. The research aim to analizying and designing a application for detect human object in image. Thinnging algorithm used to introduction pattern human object from a image for another image in order to equalize object pixel to detection maximum. The local maxima used as function for maximize searching pixel on object in image for make it easier and faster to detect image

Keywords—Thinning algorithm, Local Maxima, human object

\section{PENDAHULUAN}

Pengolahan citra, kadang diperlukan proses pencarian terhadap objek tertentu dalam sebuah citra digital. Proses ini berhubungan dengan pengenalan pola. Pola adalah entitas yang terdefinisi dan dapat diidentifikasikan melalui bentuknya (contour) [2]. Citra adalah suatu representasi (gambaran), kemiripan, atau imitasi dari suatu objek. Pengolahan citra adalah pemrosesan citra, khususnya menggunakan computer menjadi citra yang kualitasnya lebih baik 
[12]. Citra merupakan matrik dua dimensi dari fungsi intensitas cahaya, maka referensi citra menggunakan dua variabel yang menunjuk posisi pada bidang dengan sebuah fung intensitas cahaya yang dapat dituliskan sebagai $\mathrm{f}(\mathrm{x}, \mathrm{y})$ dimana $\mathrm{f}$ adalah nilai amplitudo pada koordinat spasial $(\mathrm{x}, \mathrm{y})[20]$. Face detector adalah aplikasi yang dapat mendeteksi area wajah pada sebuah image[7]. Citra digital adalah suatu ukuran frekuensi atas perubahan nilai keabuan pada piksel[9] Deteksi kecocokan objek pada citra digital berdasarkan deteksi fitur, seleksi skala, skala penghubung, pengenalan objek, relevansi skala dan afinitas, skala ruang [21]. Deteksi kecocokan objek pada citra digital berdasarkan pada histogram warna RGB.

Operasi analisis objek pada citra ini dilakukan agar mendapatkan hasil yang lebih maksimum dari piksel, seperti pengenalan karakter sidik jari. Dengan metode thinning sebagai tahapan awalnya, implikasi praktikal pada beberapa bidang telah meningkatkan pentingnya penerapan metode ini dan memerlukan algoritma yang lebih cepat dan lebih sederhana untuk mendesainnya. Citra yang di-thinning biasanya digunakan dalam Optical Character Recognition, Fingerprint classification, printed circuit boards dan sebagainya[1]

Algoritma yang tidak sama akan menggunakan pendekatan yang berbeda untuk menyelesaikan problema thinning. Secara garis besar, algoritma thinning terbagi menjadi dua kategori yaitu interatif dan non-interatif. Algoritma interatif terbagi lagi menjadi dua kelompok yaitu sekuensial dan paralel. Algoritma sekuensial menganggap semua piksel untuk mengambil keputusan terhadap sebuah piksel tunggal. Sedangkan, piksel dapat secara terpisah ditentukan keputusannya pada algoritma paralel, yaitu dengan membuang atau mempertahankan pikselnya. Salah satu contoh algoritma sekuensial adalah algoritma Generic Thinning yang diperkenalkan oleh S. Ahmed, M. Sharmin dan Chowdhury Mofizur Rahman dari Bangladesh. Algoritma ini diklaim mampu diterapkan dalam proses pengenalan huruf Bangla dan huruf Bahasa Inggris dan angka dengan performansi yang lebih baik. Algoritma lainnya yang dibahas adalah algoritma Thinning Paralel yang bertujuan untuk melakukan proses thinning, yang merupakan kombinasi dari algoritma medial axis dan contour generation. Algoritma Paralel melakukan pengelompokkan gambar (image) menjadi dua daerah, yaitu daerah lurus dan daerah kurva, dimana daerah lurus akan diperoleh dengan menggunakan metode medial axis dan curved regions diperoleh dengan menggunakan metode contour generation. Setelah itu rangka (skeletons) dari masing-masing segmen tersebut kemudian dihubungkan. Local maxima adalah suatu proses pencarian objek dengan memaksimumkan pencarian agar mendapatkan hasil yang lebih efisien, dalam pengolahan citra ini menggunakan dasar local maxima agar dapat memaksimumkan pencarian objek citra pada gambar dengan cepat dan tepat[4].

\section{METODE PENELITIAN}

Analisis sistem yang dilakukan mencakup proses analisis masalah, analisis kebutuhan fungsional dengan menggunakan use case diagram, analisis kebutuhan non fungsional dengan menggunakan kerangka PIECES. Perancangan tampilan interface pada sistem (user interface) dengan aplikasi balsamiq Mockup. Pembuatan aplikasi dilakukan proses pengkodingan (coding) sistem dengan metode image thinning berdasarkan local maxima yang dikombinasikan dengan metode learning rate menggunakan bahasa pemrograman VB.NET. Sistem yang telah selesai dibuat akan diuji dengan tujuan untuk mengetahui bagaimana cara kerja algoritma image thinning berdasarkan local maxima yang telah diimplementasikan pada sistem. Pengujian akan dilakukan untuk mengukur akurasi dari hasil klasifikasi wajah. Proses pengujian akan

Harahap, et., al [Deteksi Objek Manusia pada Image Dengan Metode Thinning Berdasarkan Local Maxima] 
menggunakan metode Confusion Matrix dan akan dilakukan pengujian terhadap total 24 buah citra dengan perincian 5 buah gambar yang didalamnya masin-masing terdiri dari satu objek manusia didalamnya, 10 buah gambar dengan dua objek manusia didalamnya, 5 buah gambar dengan empat objek manusia didalamnya, dan 2 buah gambar dengan 7 sampai 8 banyaknya objek manusia didalamnya.

Pada bagian ini penjelasan tentang penggunaan metode yang digunakan, metode yang digunakan adalah metode thinning untuk pengenalan pola objek manusia dari satu image untuk gambar yang lain agar menyamakan objek piksel untuk penditeksian yang maksimal. Proses local maxima objek untuk memaksimumkan pencarian piksel pada objek citra pada image untuk mempermudah dan mempercepat diteksi gambar dengan preprocessing thersholding. Image yang diuji adalah citra $R G B$ yang diambil dengan format $B M P$, JPG dan PNG. Jumlah objek yang dideteksi maksimal 12 objek. Ukuran citra input yang dapat diproses dibatasi 200 x 200 pixel sampai dengan 400 x 400 pixel.

\subsection{Proses Deteksi}

\subsubsection{Input Image}

Pada tahap pertama dilakukan input citra ke dalam aplikasi untuk mengawali pemrosesan. Data yang digunakan adalah data primer dimana data primer adalah data yang diperoleh langsung dari subyek penelitian. Data foto yang di ambil adalah sebuah gambar yang memiliki beberapa objek selain objek manusia.
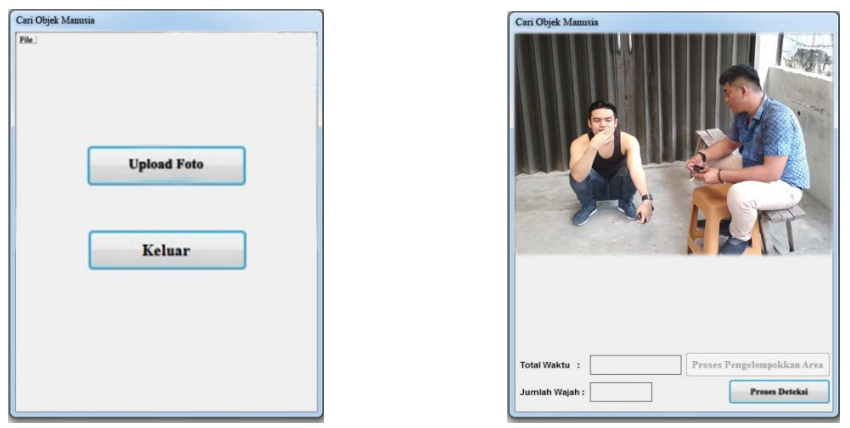

Gambar 1. Input Image

\subsubsection{Preprocessing}

Pada tahap ini proses preprocessing yang digunakan adalah enchancement (penajaman kualitas citra). Dengan menggunakan preprocessing thresholding otsu foto dapat lebih mempertajam minutiae pada citra objek, dapat di lihat pada gambar berikut ini.

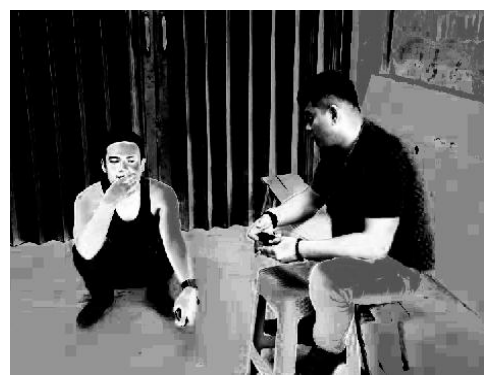

Gambar 2. Citra Asli, Citra Otsu

Harahap, et., al [Deteksi Objek Manusia pada Image Dengan Metode Thinning Berdasarkan Local Maxima] 


\subsubsection{Background Elemination}

Background Elemination dapat dilakukan dengan cara melakukan konversi dari citra berwarna ke citra biner. Sebelum konversi ke citra biner, citra akan di konversi ke citra grayscale terlebih dahulu. Proses konversi citra keabuan ke biner diperlukan untuk proses selanjutnya, yaitu proses penipisan (thinning) yang hanya bisa dilakukan pada citar biner.

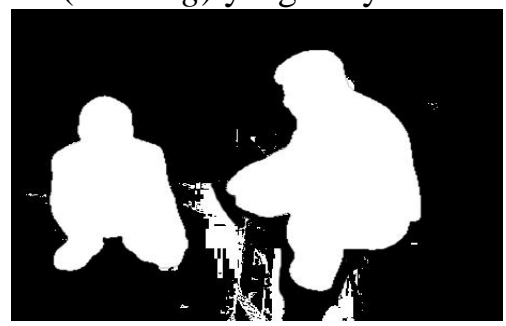

\subsubsection{Segmentasi Ciri}

Gambar 3. Konversi Citra Asli ke Biner

Pada tahap ini segmentasi dilakukan untuk mendapatkan citra tipis menggunakan metode thinning Zhang-Suen atau Stentiford. Langkah yang dilakukan pada proses ini adalah sebagai berikut:

a. Citra objek hasil preprocessing otsu dilakukan proses thinning menggunakan Zhang-Suen atau Stentiford.

b. Pada tahap ini merupakan tahapan yang dilakukan dalam segmentasi citra image. Thinning dilakukan untuk mengurangi waktu proses system dan memudahkan dalam penipisan citra image.

Hasil proses citra image menggunakan metode thinning akan ditunjukkan pada gambar berikut.

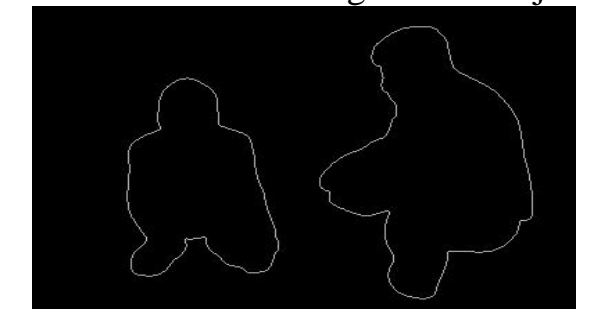

Gambar 4. Proses Thinning Citra Image

\subsubsection{Local Maxima}

Local Maxima adalah nilai terbesar dari fungsi, baik dalam kisaran tertentu atau di seluruh domain dari fungsi. Dalam masalah praktis sehari-hari nilai maksimum dan minimum sering muncul dan membutuhkan suatu cara penyelesaian. Dalam tahap ini image yang telah selesai pada tahap thinning akan langsung mencari nilai terbesar untuk penyeleksian objek manusia yang dapat di lihat pada gambar berikut.

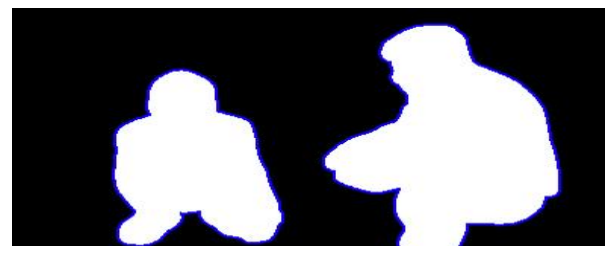

Gambar 5a. Proses Local Maxima

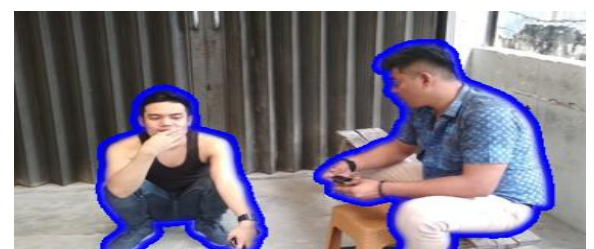

Gambar 5b. Hasil Deteksi Local Maxima

\footnotetext{
Harahap, et., al [Deteksi Objek Manusia pada Image Dengan Metode Thinning Berdasarkan Local Maxima]
} 
Jatisi

ISSN 2407-4322

Vol. 7, No. 3, Desember 2020, Hal. 617-627 E- ISSN 2503-2933

621

\subsection{Presentase Deteksi}

Presentase deteksi objek manusia pada image dihasilkan dari warna kulit dan bentuk tubuh manusia. proses kerja dari indentifikasi warna kulit manusia dapat dilihat dari contoh sederhana berikut ini.

Misalkan citra asli yang dimasukkan berupa citra berwarna, yang memiliki komposisi warna ( $\mathrm{R}$, G, B) sebagai berikut:

Tabel 1. Citra Asli Dalam Komposisi Warna RGB

\begin{tabular}{|c|c|c|c|c|c|}
\hline Piksel 0, 0: & Piksel 0, 1: & Piksel 0, 2: & Piksel 1, 0: & Piksel 1, 1: & Piksel 1, 2: \\
$101,69,54$ & $89,55,43$ & $77,50,39$ & $62,40,29$ & $126,79,49$ & $122,75,47$ \\
\hline Piksel 2, 0: & Piksel 2, 1: & Piksel 2, 2: & Piksel 3, 0: & Piksel 3, 1: & Piksel 3, 2: \\
$88,45,28$ & $64,31,24$ & $147,101,77$ & $122,74,52$ & $230,183,165$ & $155,69,53$ \\
\hline Piksel 4, 0: & Piksel 4, 1: & Piksel 4, 2: & Piksel 5, 0: & Piksel 5, 1: & Piksel 5, 2: \\
$105,59,44$ & $204,133,105$ & $133,65,56$ & $159,85,40$ & $147,71,37$ & $139,83,84$ \\
\hline
\end{tabular}

Proses identifikasi warna kulit pada manusia dapat dirincikan sebagai berikut:

a. Proses konversi citra ke bentuk grayscale.

Piksel $(1,1):(101+69+54) / 3=74.6(\approx 75)$

Piksel $(1,2):(89+55+43) / 3=62.3(\approx 62)$

Piksel $(1,3):(77+50+39) / 3=55.3(\approx 55)$

Piksel $(2,2):(62+40+29) / 3=43.6(\approx 44)$

Piksel $(2,3):(126+79+49) / 3=84.6(\approx 87)$

Piksel $(3,1):(122+75+47) / 3=81.3(\approx 81)$

Piksel $(3,2):(88+45+28) / 3=53.6(\approx 57)$

Piksel $(3,3):(64+31+24) / 3=39.6(\approx 40)$

Piksel $(4,1):(147+101+77) / 3=108.3(\approx 108)$

Piksel $(4,2):(122+74+52) / 3=82.6(\approx 83)$

Piksel $(4,3):(230+183+165) / 3=192.6(\approx 193)$

Piksel $(5,1):(155+69+53) / 3=92.3(\approx 93)$

Piksel $(5,2):(105+59+44) / 3=69.3(\approx 69)$

Piksel $(5,3):(204+133+105) / 3=147.3(\approx 147)$

Piksel $(6,1):(133+65+56) / 3=84.6(\approx 85)$

Piksel $(6,2):(159+85+40) / 3=94.6(\approx 95)$

Piksel $(6,3):(147+71+37) / 3=85$

Piksel $(7,1):(139+83+84) / 3=102$

Tabel 2. Hasil Konversi Citra ke Bentuk GrayScale

\begin{tabular}{|c|c|c|c|c|c|}
\hline 75 & 62 & 55 & 44 & 87 & 81 \\
\hline 57 & 40 & 108 & 83 & 193 & 93 \\
\hline 69 & 147 & 85 & 95 & 85 & 102 \\
\hline
\end{tabular}

b. Proses Segmentasi Objek

Konversikan citra ke bentuk gambar hitam putih. Misalkan nilai threshold $=85$, maka proses kerjanya adalah sebagai berikut:

Piksel $(1,1): 75<85 \rightarrow \mathrm{BW}=0$

Piksel $(1,2): 62<85 \rightarrow \mathrm{BW}=0$

Piksel $(1,3): 55<85 \rightarrow \mathrm{BW}=0$

Piksel $(2,2): 44<85 \rightarrow \mathrm{BW}=0$

Piksel $(2,3): 87>85 \rightarrow \mathrm{BW}=1$

Harahap, et., al [Deteksi Objek Manusia pada Image Dengan Metode Thinning Berdasarkan Local Maxima] 
Piksel $(3,1): 81<85 \rightarrow \mathrm{BW}=0$

Piksel $(3,2): 57<85 \rightarrow \mathrm{BW}=0$

Piksel $(3,3): 40<85 \rightarrow \mathrm{BW}=0$

Piksel $(4,1): 108>85 \rightarrow \mathrm{BW}=1$

Piksel $(4,2): 83<85 \rightarrow \mathrm{BW}=0$

Piksel $(4,3): 193>85 \rightarrow \mathrm{BW}=1$

Piksel $(5,1): 93>85 \rightarrow \mathrm{BW}=1$

Piksel $(5,2): 69<85 \rightarrow \mathrm{BW}=0$

Piksel $(5,3): 147>85 \rightarrow$ BW $=1$

Piksel $(6,1): 85 \neq 85 \rightarrow \mathrm{BW}=0$

Piksel $(6,2): 95>85 \rightarrow \mathrm{BW}=1$

Piksel $(6,3): 85 \neq 85 \rightarrow \mathrm{BW}=0$

Piksel $(7,1): 102>85 \rightarrow \mathrm{BW}=1$

Tabel 3. Hasil Konversi Citra ke Bentuk Gambar Hitam Putih

\begin{tabular}{|l|l|l|l|l|l|}
\hline 0 & 0 & 0 & 0 & 1 & 0 \\
\hline 0 & 0 & 1 & 0 & 1 & 1 \\
\hline 0 & 1 & 0 & 1 & 0 & 1 \\
\hline
\end{tabular}

c. Proses Pengelompokkan Area yang Terdeteksi

Sebuah piksel (titik) dimasukkan ke dalam sebuah area apabila piksel tersebut merupakan piksel tetangga dari salah satu piksel yang terdapat pada area yang terdeteksi seperti terlihat pada ilustrasi berikut:

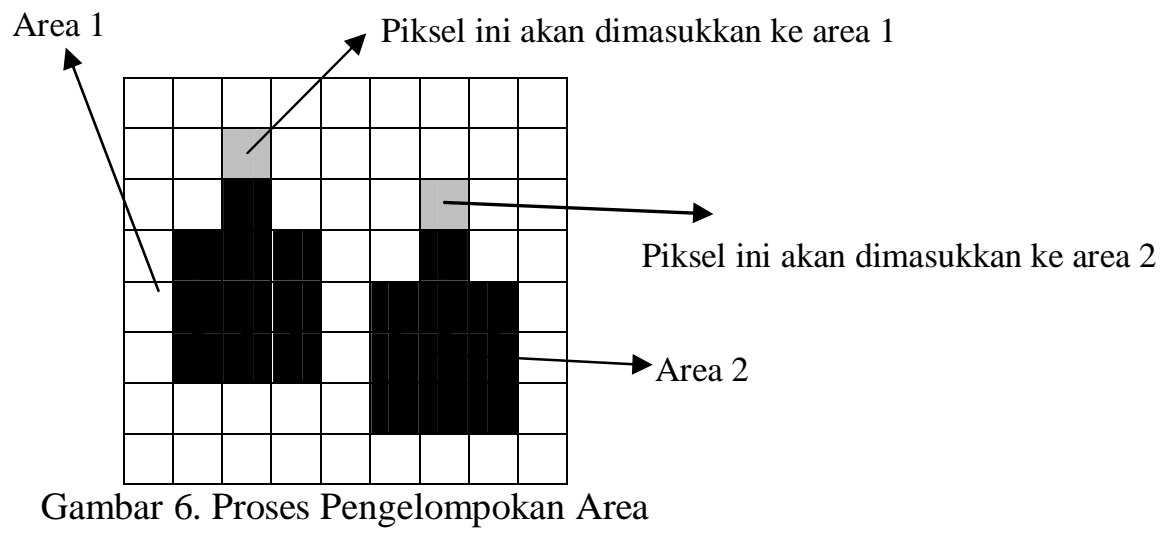

\section{HASIL DAN PEMBAHASAN}

\subsection{Hasil}

Hasil dari aplikasi pendeteksian objek manusia ini dapat dilihat pada gambar berikut: 
Tabel 4. Hasil Pendeteksi Objek Manusia pada Gambar

\begin{tabular}{|c|c|c|c|c|c|}
\hline \multirow{2}{*}{ No. } & \multicolumn{2}{|c|}{ Objek Manusia } & \multicolumn{2}{|c|}{ Presensi } & \multirow[t]{2}{*}{ Keterangan } \\
\hline & Gambar Asli & Hasil Deteksi & Berhasil & Gagal & \\
\hline 1 & & & $80 \%$ & $20 \%$ & $\begin{array}{lr}\text { Objek } & \text { manusia } \\
\text { dapat } & \text { terdeteksi } \\
\text { dan } & \text { ditemuka } \\
\text { citra } & \text { objek } \\
\text { manusia } & \text { pada } \\
\text { gambar } & \text { yang di } \\
\text { input. } & \end{array}$ \\
\hline 2 & & & ....... & $\ldots$. & p........ \\
\hline 20 & & & $80 \%$ & $20 \%$ & $\begin{array}{lr}\text { Objek } & \text { manusia } \\
\text { dapat } & \text { terdeteksi } \\
\text { dan ditemuka } & 4 \\
\text { citra } & \text { Objek } \\
\text { manusia } & \text { pada } \\
\text { gambar yang } & \text { di } \\
\text { input. } & \\
\end{array}$ \\
\hline 21 & & Cas & $80 \%$ & $20 \%$ & $\begin{array}{lr}\text { Objek } & \text { manusia } \\
\text { dapat } & \text { terdeteksi } \\
\text { dan ditemuka } 7 \\
\text { citra } & \text { Objek } \\
\text { manusia } & \text { pada } \\
\text { gambar yang di } \\
\text { input. }\end{array}$ \\
\hline 22 & & 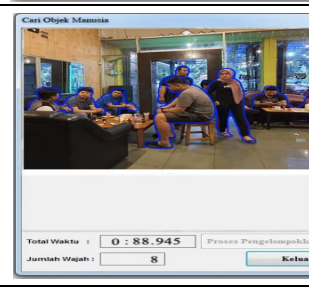 & $70 \%$ & $30 \%$ & $\begin{array}{lr}\text { Objek } & \text { manusia } \\
\text { dapat } & \text { terdeteksi } \\
\text { dan ditemuka } 8 \\
\text { citra } & \text { Objek } \\
\text { manusia pada } \\
\text { gambar yang di } \\
\text { input. }\end{array}$ \\
\hline 23 & 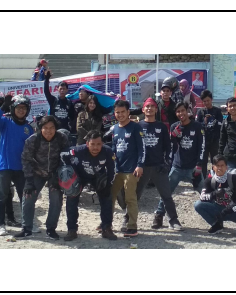 & {$\left[\begin{array}{ll}0.98 .321 \\
12\end{array}\right]$} & $70 \%$ & $30 \%$ & $\begin{array}{lr}\text { Objek } & \text { manusia } \\
\text { dapat } & \text { terdeteksi } \\
\text { dan ditemuka } 11 \\
\text { citra } & \text { Objek } \\
\text { manusia } & \text { pada } \\
\text { gambar yang di } \\
\text { input. }\end{array}$ \\
\hline 24 & & 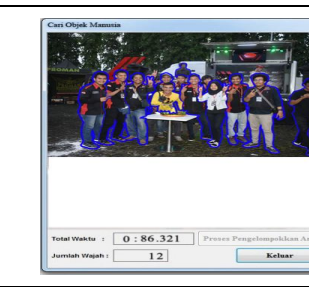 & $70 \%$ & $30 \%$ & $\begin{array}{lr}\text { Objek } & \text { manusia } \\
\text { dapat } & \text { terdeteksi } \\
\text { dan ditemuka } 12 \\
\text { citra } & \text { Objek } \\
\text { manusia pada } \\
\text { gambar yang di } \\
\text { input. }\end{array}$ \\
\hline
\end{tabular}

Berdasarkan hasil pengujian yang dilakukan terhadap sistem yang dirancang, maka dapat dirangkum dalam bentuk tabel sebagai berikut: 
Tabel 5. Hasil Pengujian

\begin{tabular}{|c|c|c|c|c|c|}
\hline \multirow[b]{2}{*}{ Pengujian } & \multicolumn{2}{|c|}{ Jumlah Objek Terdeteksi } & \multicolumn{2}{|c|}{ Acurary } & \multirow[b]{2}{*}{ Keterangan } \\
\hline & $\begin{array}{c}\text { Keadaan } \\
\text { Sebenarnya }\end{array}$ & $\begin{array}{c}\text { Hasil Monitoring } \\
\text { Sistem }\end{array}$ & Berhasil & Gagal & \\
\hline 1 & 1 & 1 & $80 \%$ & $20 \%$ & Berhasil \\
\hline 2 & 1 & 1 & $80 \%$ & $20 \%$ & Berhasil \\
\hline 3 & 1 & 0 & $0 \%$ & $100 \%$ & GAGAL \\
\hline 4 & 1 & 1 & $80 \%$ & $20 \%$ & Berhasil \\
\hline 5 & 1 & 1 & $80 \%$ & $20 \%$ & Berhasil \\
\hline 6 & 2 & 2 & $70 \%$ & $30 \%$ & Berhasil \\
\hline 7 & 2 & 2 & $70 \%$ & $30 \%$ & Berhasil \\
\hline 8 & 2 & 2 & $70 \%$ & $30 \%$ & Berhasil \\
\hline 9 & 2 & 0 & $0 \%$ & $100 \%$ & GAGAL \\
\hline 10 & 2 & 1 & $30 \%$ & $70 \%$ & GAGAL \\
\hline 11 & 2 & 2 & $80 \%$ & $20 \%$ & Berhasil \\
\hline 12 & 2 & 2 & $70 \%$ & $30 \%$ & Berhasil \\
\hline 13 & 2 & 1 & $30 \%$ & $70 \%$ & GAGAL \\
\hline 14 & 2 & 2 & $80 \%$ & $20 \%$ & Berhasil \\
\hline 15 & 2 & 2 & $50 \%$ & $50 \%$ & Berhasil \\
\hline 16 & 4 & 3 & $75 \%$ & $25 \%$ & Berhasil \\
\hline 17 & 7 & 4 & $70 \%$ & $30 \%$ & Berhasil \\
\hline 18 & 4 & 3 & $75 \%$ & $25 \%$ & Berhasil \\
\hline 19 & 5 & 4 & $80 \%$ & $20 \%$ & Berhasil \\
\hline 20 & 4 & 4 & $80 \%$ & $20 \%$ & Berhasil \\
\hline 21 & 8 & 7 & $80 \%$ & $20 \%$ & Berhasil \\
\hline 22 & 11 & 8 & $70 \%$ & $30 \%$ & Berhasil \\
\hline 23 & 11 & 11 & $70 \%$ & $30 \%$ & Berhasil \\
\hline 24 & 12 & 12 & $70 \%$ & $30 \%$ & Berhasil \\
\hline
\end{tabular}

Hasil yang diperoleh:

Accuracy : $18 / 10 * 100 \%=80 \%$

Error Rate: $4 / 10 * 100 \%=20 \%$

Berdasarkan hasil pengujian diatas dapat diperoleh akurasi deteksi objek manusia pada image sebesar $80 \%$.

\subsection{Pembahasan}

Dari hasil pengujian yang dilakukan, maka untuk kemungkinan persentasi akurasi objek terdeteksi menjadi $100 \%$ tidak di dapatkan, karena objek yang terseleksi tidak memiliki bentuk tubuh yang utuh, oleh karena itu hasil pengujian keakurasian persentasinya adalah $80 \%$ keberhasilan dalam mengindentifikasi objek manusia pada image. Dalam identifikasi objek manusia pada gambar membutuhkan pengenalan warna kulit, bentuk wajah dan kemungkinan dari bentuk tubuh seseorang agar dapat teridentifikasi, oleh karna itu dalam suatu proses memiliki nilai akurasi $80 \%$ dan nilai error $20 \%$. Error terjadi karena local maxima tidak mampu mendeteksi citra pixel yang tidak jelas pada warna kulit, wajah dan dari bentuk tubuh seseorang tersebut.

\section{KESIMPULAN}

Berdasarkan hasil yang pengujian pada aplikasi Deteksi Objek Manusia dengan dengan Algoritma Thinning berdasarkan local maxima, dapat mempermudah dalam membedakan objek manusia yang ada dalam image. Berikut ini beberapa kesimpulan yang diperoleh:

Harahap, et., al [Deteksi Objek Manusia pada Image Dengan Metode Thinning Berdasarkan Local Maxima] 
1. Proses pendeteksian citra untuk jumlah manusia yang banyak masih kurang bagus. Aplikasi akan mengalami kegagalan dalam proses pendeteksian wajah apabila gambar manusia berdekatan ataupun beberapa gambar wajah menjadi terhubung karena warna latar mendekati warna kulit.

2. Untuk gambar citra dengan satu wajah manusia memiliki tingkat keberhasilan sebesar $80 \%$, baik untuk gambar wajah dengan beragam jenis pencahayaan dan $20 \%$ adalah Gambar wajah yang dihalangi objek lain, menghadap ke samping dan dengan warna latar bervariasi.

\section{SARAN}

Berikut adalah saran dalam upaya memperludah dalam membedakan objek manusia pada beberapa saran yang ingin penulis sampaikan adalah sebagai berikut:

1. Untuk meningkatkan akurasi dari metode yang digunakan, maka dapat dikombinasikan dengan algoritma pendeteksian wajah sehingga proses pengenalan wajah hanya terhadap daerah wajah saja.

2. Mengoptimalkan waktu eksekusi dengan memperbaiki algoritma atau dengan menggunakan bahasa pemrograman lainnya.

\section{DAFTAR PUSTAKA}

[1] F. Faiza Alif, Rahmadwati, Wijono. 2016, Thinning Zhang-Suen dan Stenti Ford Untuk Menentukan Ekstraksi Ciri (Minutiae) Sebagai Identifikasi Pola Sidik Jari Whorl dan Loop, Universitas Brawijaya.

[2] J. Chi, Z. Yuchen, B. Sivaraman, W. Martin. J, J. Michael. I, 2016, Local Maxima in the Likelihood of Gaussian Mixture Models: Structural Results and Algorithmic Consequences, Conference on Neural Information Processing System, Bacelona, Spain,

[3] S. Hunter, 2018, Local Maxima of Quadratic Boolean Functions, Department of Mathematics, Harvard.

[4] H, Ayu. 2018, Segmentasi Skeleton Manusia Dengan Menggunakan Metode Filter dan Thinning, Sistem Informasi, Universitas Gunadarma.

[5] N. Kadinar, T. Tia. 2018, Deteksi Temu Ruas Daun Sirih Menggunakan Algoritma Thinning, Jawa Barat.

[6] H. Ayu, 2017, Segmentasi Citra Bentuk dan Rangka Tubuh Manusia dengan Menggunakan Metode Median Filter dan Thinning, Sistem Informasi, Universitas Gunadarma.

[7] K. Raj, K. Sandeep, R. Manish, K. Sanket, 2013, An ECG Data Compression Method Via Local Maxima and ASCII Character Enconding.

[8] Ayndri Nico Prayudo, Okky Nobian, Setyadi, A. 2015, Aplikasi Pengenalan Warna Citra Dasar, Jurnal Ilmiah Widya Teknik, 14(1), 26-31. 
[9] Santoso, S., \& Handoyo, E. D. 2015, Kombinasi Penggunaan Model Warna Dalam Pendeteksian Letak Bibir pada Gambar Digital Berwarna, Jurnal Teknik Informatika Dan Sistem Informasi. https://doi.org/10.28932/jutisi.v1i2.366

[10] Mohammad Mahmudul Alam Mia, S. K. 2015, An Algorithm for Training Multilayer Perceptron (MLP) for Image Reconstruction Using Neural Network Without Overfitting. International Journal of Scientific \& Technology.

[11] Dr.P.Ponmuthuramalingam, R. d. 2016, Neural Networks Based Image Retrieval System Using Rosenblatt's Perceptron Algorithm. International Journal of Emerging Trends \& Technology in Computer Science (IJETTCS), India.

[12] Hassan Ramchoun, M. A. 2016, Multilayer Perceptron: Architecture Optimization and Training. Morocco: International Journal of Interactive Multimedia and Artificial Intelligence.

[13] Afirianto, T., \& Amalia, F. 2017, Model Warna HSCbCrAB untuk Deteksi Kulit Menggunakan PCA-KNN, Jurnal INFORM, https://doi.org/10.25139/ojsinf.v2i2.312

[14] C. Dan, S. Armin, 2016, Online Supplement to "Multiple Testing of Local Maxima for Detection of Peaks in Random Fields". https://www.ncbi.nlm.nih.gov/pmc/articles/PMC67465 60

[15] Cheng Dan and Schwartzman Armin. 2015, Distribution of the height of local maxima of Gaussian random fields. Extremes, 18(2):213-240.

[16] D. B. Korovinskiy, N. V. Erkaev, V. S. Semenov, I. B. Ivanov, S.A. Kiehas, I. I. Ryzhkov. 2018, On The Influence of The Local Maxima of Total Pressure on The Current Sheet Stability to The Kink-Like (flapping) mode. https://aip.scitation.org/doi/full/10.1063/1. 5016934

[17] Ayu Hardianti. 2018, Segmentasi Skeleton Manusia dengan Menggunakan Metode Median Filter dan Thinning.

[18] Zhong-Qiu Zhao, Peng Zheng, Shou-tao, Xindong Wu. 2018, Object Detection with Deep Learning: A Review.

[19] Khairul Umam, Benny Sukma Negara. 2016, Deteksi Objek Manusia pada Basis Data Vidio Menggunakan Metode Background Subtraction dan Operasi Morfologi.

[20] Faiza Alif Fakhrina, Rahmadwati, Wijono. 2016, Thinning Zhang-Suen dan Stentiford untuk Menentukan Ekstraksi Ciri (Minutiae) Sebagai Identifikasi Pola Sidik Jari Whorl dan Loop. 
Jatisi

ISSN 2407-4322

Vol. 7, No. 3, Desember 2020, Hal. 617-627 E- ISSN 2503-2933

[21] Yosef Yudha, Dhesa Ardhiyanta, Laurensius Haris, dan Anastasia Rita Widiarti, 2016, Aplikasi Pengenalan Citra Warna Dasar, Jurnal Ilmiah Widya Teknik, Volume 15 Nomor 1 2016, ISSN 123.456.7890. 